\title{
Discrepancies between the isolation of Salmonella from mesenteric lymph nodes and the results of serological screening in slaughter pigs
}

\author{
Nathalie NOLLET ${ }^{\mathrm{a}, \mathrm{b} *}$, Dominiek MAES ${ }^{\mathrm{b}}$, Luc DUCHATEAU $^{\mathrm{c}}$, \\ Veerle HAUTEKIET ${ }^{\mathrm{d}}$, Kurt HOUF ${ }^{\mathrm{a}}$, Jan VAN HOOF ${ }^{\mathrm{a}}$, Lieven De ZUTTER ${ }^{\mathrm{a}}$, \\ Aart DE KRUIF ${ }^{\mathrm{b}}$, Rony GEERS ${ }^{\mathrm{d}}$ \\ ${ }^{a}$ Department of Veterinary Public Health and Food Safety, Faculty of Veterinary Medicine, \\ Ghent University, Salisburylaan 133, 9820 Merelbeke, Belgium \\ ${ }^{b}$ Department of Reproduction, Obstetrics and Herd Health, Faculty of Veterinary Medicine, \\ Ghent University, Salisburylaan 133, 9820 Merelbeke, Belgium \\ ${ }^{\mathrm{c}}$ Department of Physiology, Biochemistry and Biometrics, Faculty of Veterinary Medicine, \\ Ghent University, Salisburylaan 133, 9820 Merelbeke, Belgium \\ ${ }^{\mathrm{d}}$ Laboratory for Quality Care in Animal Production, Zootechnical Centre, K.U. Leuven, \\ Bijzondere Weg 12, 3360 Lovenjoel, Belgium
}

(Received 8 July 2004; accepted 9 November 2004)

\begin{abstract}
Most Salmonella control programmes are based on serological testing in the slaughterhouse. However, from a point of view of carcass contamination, it is rather the presence of Salmonella spp. in the animal at the time of slaughter that is important. The aim of this crosssectional study was to investigate the possible discrepancies between the isolation of Salmonella spp. in the mesenteric lymph nodes and the results of serological screening. In total, 1821 fattening pigs originating from 60 Belgian farrow-to-finish herds were sampled in the slaughterhouse. The serum samples were analysed using an indirect mix-ELISA for the presence of Salmonella antibodies and evaluated at 3 cut-off values namely 10, 20, and 40\% Optical Density (OD). All mesenteric lymph node samples were submitted to qualitative Salmonella isolation and a representative number of isolates was serotyped. From each herd, 30 animals were screened both serologically and bacteriologically and the herd was considered as positive when at least one sample was positive. At the herd level, $83.6 \%$ (cut-off OD 40\%) to 100.0\% (cut-off OD 10\%) of the herds from which Salmonella had been isolated were evaluated as seropositive. At the individual level, only $34.5 \%$ (cut-off OD $40 \%$ ) to $82.8 \%$ (cut-off OD 10\%) of the animals from which Salmonella had been isolated were seropositive. Overall, a weak agreement was found between bacteriology and serology for Salmonella diagnosis. If pig herds are categorised using serological tests in the slaughterhouse, one should be aware of the fact that slaughter pigs can still harbour Salmonella spp. in the mesenteric lymph nodes, without being detected in serological tests. The cut-off value used to evaluate a sample as serologically positive and the number of samples per herd are of major importance to classify herds correctly in order to protect human health.
\end{abstract}

slaughter pig / Salmonella / bacteriology / serology

* Corresponding author: nathalie.nollet@UGent.be 


\section{INTRODUCTION}

Salmonella is one of the most important causes of foodborne illness in humans, with eggs, poultry meat and pork as the major sources [3, 6, 34]. In Denmark [17], Germany [23] and Ireland [25], national control programmes, based on serological testing, are implemented in the pork production chain. Therefore, meat juice samples from a representative number of pigs per herd are collected at the slaughterhouse. All samples are processed using an indirect mix-ELISA, which combines different O-antigens. Such tests are, as generally accepted, a useful tool to determine the prevalence at the herd level $[18,19]$ and to point out high-prevalence herds [17]. Depending on the prevalence as determined in these tests, herds are classified into different categories [17, 23, 25].

However, with regards to the system of logistic slaughtering, it is the number of Salmonella harbouring animals, with Salmonella spp. being present in the intestines or the associated lymph nodes that is important with regards to contamination of the carcasses [5]. In many studies, the association between serological and bacteriological results as measured in faecal samples has been calculated at the herd level $[9,11$, $16,25,28,33]$ and at the individual level ${ }^{1}$ $[10,28]$. The authors agree that the serological test is suitable for screening on a herd basis in control programmes aiming to reduce Salmonella prevalence in pork. However, no predictions concerning the Salmonella carrier status can be made with certainty based on serological testing, especially not at the individual level.

During transport and lairage, the number of Salmonella shedders can be doubled within 2-6 h, as has been shown in a Dutch study [4]. This increase in the number of shedding animals is caused by pigs excreting Salmonella spp. already at the herd but also by pigs with reactivated latent infections, harbouring Salmonella spp. in the intestines and the gut associated lymph

${ }^{1}$ Dahl J., unpublished results. nodes [4]. Because the risk for cross-contamination during transport and lairage is high, individual faecal samples taken at the slaughterhouse could overestimate the herd prevalence. A better estimation of the herd prevalence can be made by determining the number of Salmonella infected animals based on isolation of Salmonella spp. in the mesenteric lymph nodes [8, 14, 30]. Because most of the existing Salmonella control programmes are based on serological diagnosis, it is important to know how many of the Salmonella seronegative herds can still deliver Salmonella infected animals at the slaughterhouse.

The aim of the present study was to determine how many of the animals that are Salmonella culture positive, as obtained by Salmonella isolation in the mesenteric lymph nodes collected at the slaughterhouse, are also serologically positive. The discrepancy between the bacteriological and serological status was evaluated at the herd level and at the individual level and was additionally determined for the 5 most-occurring serotypes.

\section{MATERIALS AND METHODS}

\subsection{Selection of the herds and study population}

Sixty farrow-to-finish pig herds were included in this cross-sectional study. All herds were regular suppliers of one of the four slaughterhouses belonging to one cooperative. They were all located in Flanders (Belgium) and had a minimum herd size of 100 sows. From each herd, 30 pigs were identified and sampled from an average slaughterhouse delivery of about 95 pigs. The selection of the pigs was done systematically with randomisation of the first pig. More details about the studied population are described in a previous paper [22].

\subsection{Sample collection}

The samples were collected at the four slaughterhouses over a time period of 
one year. Blood samples from each study pig were taken at exsanguination. After evisceration, the intestines were individually identified and mesenteric lymph nodes were collected from the ileum. All samples were immediately transported to the laboratory for further processing.

\subsection{Sample analyses}

\subsubsection{Serum samples}

The blood samples were centrifuged at $1400 \times g$ for $10 \mathrm{~min}$. All serum samples were stored at $-20{ }^{\circ} \mathrm{C}$ until the end of the trial. Then, they were analysed using a commercial indirect mix-ELISA, following the recommendations of the manufacturer (HerdCheck Swine Salmonella Antibody Test Kit, Idexx Laboratories, Inc., Maine, USA). The presence of antibodies against Salmonella in each sample was determined by relating the absorbance value at $650 \mathrm{~nm}$ of the unknown to the positive control mean by calculating the Sample-to-Positive (S/P) ratio. S/P values were associated with Optical Density percentages (OD\%) by an experimentally determined correlation factor of 2.5, which was based on German and Dutch reference samples and on an international ring trial [31]. OD\% can be calculated by the following formula:

$$
O D \%=\left(\frac{S / P}{2.5}\right) \times 100 .
$$

\subsubsection{Mesenteric lymph node samples}

First, all lymph nodes were immersed for $10 \mathrm{~s}$ in $95 \%$ ethanol followed by flaming to decontaminate the surface $[8,14]$. Ten grams were aseptically transferred to sterile stomacher bags and $90 \mathrm{~mL}$ Buffered Peptone Water (CM 509, Oxoid Ltd., Basingstoke, Hampshire, England) was added. After homogenisation during $1 \mathrm{~min}$ with a stomacher blender, the homogenates were incubated at $37{ }^{\circ} \mathrm{C}$ for 16 to $20 \mathrm{~h}$. Following incubation, $100 \mu \mathrm{L}$ were added to $10 \mathrm{~mL}$ of
Rappaport-Vassiliadis (RV) broth (CM 669, Oxoid) and $100 \mu \mathrm{L}$ was spotted onto a Modified Semisolid Rappaport-Vassiliadis agar (MSRV) plate (LAB 150, Lab M, Lancashire, UK). Both media were incubated for $24 \mathrm{~h}$ at $42^{\circ} \mathrm{C}$. The MSRV plates were examined for the presence of migration zones. A loopful of the culture edge of the migration zones and of each RV enrichment broth was streaked on a Xylose Lysine Desoxycholate (XLD) agar plate (CM 469, Oxoid). After incubation for $24 \mathrm{~h}$ at $37^{\circ} \mathrm{C}$, all XLD plates were examined for the presence of suspected colonies. The collected strains were biochemically tested using Triple Sugar Iron, Indol and Lysine. From an average of 9 randomly selected strains per herd, one Salmonella colony per sample was stored at $-20^{\circ} \mathrm{C}$ for further identification of the isolate.

\subsection{Identification of the isolates}

Isolates belonging to serotype Typhimurium were first identified by the polymerase chain reaction (PCR) assay using the Salmonella Typhimurium-specific primers MDH 31 and MDH 2 coding for malic acid dehydrogenase [15]. Briefly, the isolates were grown on Plate Count Agar (CM 325, Oxoid) for $24 \mathrm{~h}$ at $37^{\circ} \mathrm{C}$ under aerobic conditions. One colony was harvested and suspended in $150 \mu \mathrm{L}$ sterile water and heated for $15 \mathrm{~min}$ at $90^{\circ} \mathrm{C}$. The suspensions were centrifuged for $1 \mathrm{~min}$ at $11000 \times g$ and $2 \mu \mathrm{L}$ of the supernatant was used in the PCR assay. PCR reactions were performed in a reaction mixture $(50 \mu \mathrm{L}$ final volume) containing $5 \mu \mathrm{L}$ of $10 \times$ PCR buffer (Eurogentec, Seraing, Belgium), 1 U of Taq DNA polymerase (Yellow star, Eurogentec), 200 pmol each of dATP, dGTP, dCTP, and dTTP, $1.25 \mathrm{mmol} \mathrm{L}^{-1} \mathrm{MgCl}_{2}$, and 50 pmol each of the PCR primers. PCR involved 35 cycles of denaturation $\left(94^{\circ} \mathrm{C}, 20 \mathrm{~s}\right)$, primer annealing $\left(67^{\circ} \mathrm{C}, 30 \mathrm{~s}\right)$ and chain extension $\left(72{ }^{\circ} \mathrm{C}, 30 \mathrm{~s}\right)$. Prior to cycling, the samples were heated at $94{ }^{\circ} \mathrm{C}$ for $3 \mathrm{~min}$. The amplified products were detected by electrophoresis in $1.5 \%$ agarose in $0.5 \times$ Trisborate-EDTA buffer at $100 \mathrm{~V}$ for $40 \mathrm{~min}$. 
The gels were stained with ethidium bromide. An UV transilluminator was used for visualisation.

The isolates that tested negative in the PCR assay were serotyped according to the Kauffman-White Scheme [24], which is based on somatic (O or lipopolysaccharide) and flagellar $(\mathrm{H})$ antigens.

\subsection{Statistical analyses}

Three different cut-off values were considered in the interpretation of the serological results: OD $10 \%$, OD $20 \%$ and OD $40 \%$. The first value is recommended by the manufacturer (Idexx Laboratories, Inc., Maine, USA). The value of OD $40 \%$ has been experimentally determined as the optimal value for large scale use in the original Danish Salmonella surveillance and control programme [17], but this value has recently been decreased to the cut-off value of OD $20 \%$ [20]. Values lower than the cut-off value were considered as negative, values equal to or higher than the cut-off value were considered as positive, following the recommendations of the manufacturer (Idexx Laboratories, Inc.).

First, logistic regression was used to model the presence of a bacteriological infection as a function of the continuous OD\% value. Next, the OD\% value was replaced by a binary variable expressing whether the sample was seronegative or not.

The relative sensitivity of the serological test was estimated by the number of serologically positive samples that was also bacteriologically positive. The relative sensitivity of Salmonella isolation in the mesenteric lymph nodes was estimated in a similar way. All sensitivities were investigated at the herd level and at the individual level. For the analysis at the herd level, a herd was considered as positive if at least one sample was found positive. The probability for classifying a herd as serologically positive given the herd was bacteriologically positive was calculated for different sample sizes based on the binomial distri- bution and assuming independence between the samples of a herd.

Additionally, as a measure of agreement between both diagnostic tests, Cohen kappa coefficients were calculated at the herd level and the individual level, and for the different cut-off values.

The relative sensitivities were also derived for each of the 5 serotypes that were most prevalent. The latter sensitivities were compared with each other using Chi-square tests.

All statistical analyses were performed using SAS 8.0.

\section{RESULTS}

\subsection{Descriptive results}

In total, 1821 pigs from 60 herds were sampled. The descriptive results for the bacteriology and serology using the different cut-off values are given in Table I. From the 492 isolates that were serotyped, 23 different serotypes were found. The 5 most common serotypes were $S$. Typhimurium (33.0\%), S. Derby (26.0\%), S. Goldcoast (11.0\%), S. Panama (7.0\%) and S. Livingstone $(7.0 \%)$. Other important serotypes were $S$. London $(4.0 \%), S$. Rissen $(4.0 \%)$, $S$. Brandenburg $(3.0 \%)$ and $S$. Anatum $(2.0 \%)$.

\subsection{Association between bacteriological and serological results}

The OR $(95 \% \mathrm{CI})$ for an animal being Salmonella positive in the mesenteric lymph nodes was 1.10 (1.07-1.14) for an increase of the OD with $10 \%$. The OR $(95 \%$ CI) for being Salmonella positive in the mesenteric lymph nodes for OD\% above versus below the cut-off value was 2.07 (1.66-2.59), $1.67(1.38-2.01)$ and 1.70 (1.372.09 ) for the cut-off values of $10 \%, 20 \%$ and $40 \%$, respectively.

The individual results for the Salmonella isolation in the mesenteric lymph nodes and the serological results for the cut-off values 
Table I. Descriptive results for Salmonella enterica based on bacteriological isolation in the mesenteric lymph nodes (MLN) and serology. In total, 1821 samples were taken from 60 Belgian farrow-to-finish herds during 2001-2002.

\begin{tabular}{|c|c|c|c|c|}
\hline & \multicolumn{4}{|c|}{ Serology with different cut-off values } \\
\hline & MLN & $\mathrm{OD}^{\mathrm{b}} 10 \%$ & OD $20 \%$ & OD $40 \%$ \\
\hline Number of positive isolates & 1066 & 1348 & 991 & 547 \\
\hline$\%$ of positive herds ${ }^{\mathrm{a}}$ & 91.7 & 100.0 & 96.7 & 83.3 \\
\hline$\%$ of positive samples per herd $( \pm$ SD) & $57.3 \pm 36.73$ & $76.8 \pm 24.02$ & $53.3 \pm 31.24$ & $29.0 \pm 27.82$ \\
\hline
\end{tabular}

a A herd was defined as positive if at least one sample was found positive.

b Optical density: values lower than the cut-off value were considered as negative, values equal to or higher than the cut-off value as positive.

Table II. Two by two table for the Salmonella isolation results in the mesenteric lymph nodes (MLN) and the serological test using the cut-off value of OD 10\%. In total, 30 pigs from 60 Belgian farrowto-finish herds were sampled ( $n=1821)$ during 2001-2002.

\begin{tabular}{lccc}
\hline & Serologically negative $^{\mathrm{b}}$ & Serologically positive & Total \\
\hline MLN $^{\mathrm{a}}$ negative & 227 & 528 & 755 \\
MLN positive & 183 & 883 & 1066 \\
Total & 410 & 1411 & 1821 \\
\hline
\end{tabular}

a The results of the qualitative Salmonella isolation from the mesenteric lymph nodes. The results are expressed as either positive or negative.

$\mathrm{b}$ The results of the serological testing using a cut-off value of OD 10\%. The results are expressed as either positive or negative.

Table III. Two by two table for the Salmonella isolation results in the mesenteric lymph nodes (MLN) and the serological test using the cut-off value of OD $20 \%$. In total, 30 pigs from 60 Belgian farrowto-finish herds were sampled $(n=1821)$ during 2001-2002.

\begin{tabular}{lccc}
\hline & Serologically negative $^{\mathrm{b}}$ & Serologically positive & Total \\
\hline MLN $^{\mathrm{a}}$ negative & 400 & 355 & 755 \\
MLN positive & 430 & 636 & 1066 \\
Total & 830 & 991 & 1821 \\
\hline
\end{tabular}

a The results of the qualitative Salmonella isolation from the mesenteric lymph nodes. The results are expressed as either positive or negative.

$\mathrm{b}$ The results of the serological testing using a cut-off value of OD 20\%. The results are expressed as either positive or negative.

of OD $10 \%, 20 \%$ and $40 \%$ are shown in Tables II, III and IV, respectively. The relative sensitivity (95\% C.I.) for the serological test at the individual level was 82.8 (80.6-85.1), 59.7 (56.7-62.6) and 34.5 (31.7-37.5) for the cut-off values of OD
$10 \%, 20 \%$ and $40 \%$, respectively. At the herd level, a relative sensitivity (95\% C.I.) of 100.0 (93.5-100.0), 98.2 (90.3-100.0) and 83.6 (71.2-92.2) was found for the cutoff values of OD 10\%, 20\% and $40 \%$, respectively. The relative sensitivity $(95 \%$ 
Table IV. Two by two table for the Salmonella isolation results in the mesenteric lymph nodes (MLN) and the serological test using the cut-off value of OD $40 \%$. In total, 30 pigs from 60 Belgian farrowto-finish herds were sampled $(n=1821)$ during 2001-2002.

\begin{tabular}{lccc}
\hline & Serologically negative $^{\mathrm{b}}$ & Serologically positive & Total \\
\hline MLN $^{\mathrm{a}}$ negative & 576 & 179 & 755 \\
MLN positive & 698 & 368 & 1066 \\
Total & 1274 & 547 & 1821 \\
\hline
\end{tabular}

a The results of the qualitative Salmonella isolation from the mesenteric lymph nodes. The results are expressed as either positive or negative.

$\mathrm{b}$ The results of the serological testing using a cut-off value of OD $40 \%$. The results are expressed as either positive or negative.

C.I.) for the Salmonella isolation at the individual level was $62.6(60.0-65.1), 64.2$ (61.1-67.2) and $67.3(63.3-71.2)$ for the cut-off values of OD $10 \%, 20 \%$ and $40 \%$, respectively. At the herd level, a relative sensitivity (95\% C.I.) of 91.7 (81.6-97.2), $93.1(83.3-98.1)$ and $93.9(83.1-98.7)$ was found for the cut-off values of OD $10 \%$, $20 \%$ and $40 \%$, respectively.

The probability of a herd to be correctly classified as serologically positive using different cut-off values as a function of the sample size and assuming independence between different samples of a herd is shown in Figure 1. When analysing 5 serum samples per herd, the probability of classi- fying a Salmonella culture positive herd as seropositive is $87.9 \%, 98.9 \%$ and $100.0 \%$ for the cut-off values OD $40 \%, 20 \%$ and $10 \%$, respectively. If 20 serum samples were analysed, the probability of correctly classifying an isolation positive herd as seropositive is $100.0 \%$ for the 3 cut-off values.

Because all herds were serologically positive at the cut-off values of OD\% 10, no Cohen kappa coefficient between the bacteriological and the serological diagnostic technique could be calculated. The Cohen kappa coefficients at the herd level for the cut-off values 20 and 40 OD\% were 0.25 and 0.15 , respectively. The Cohen kappa

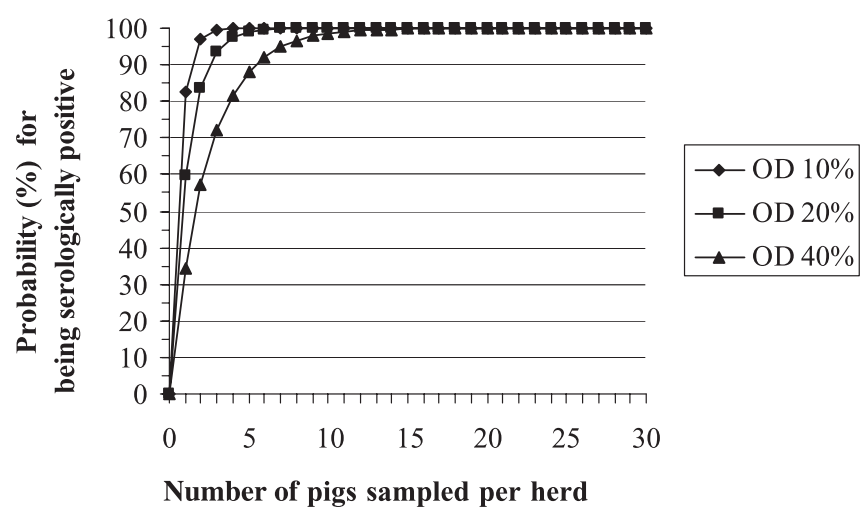

Figure 1. The probability of classifying a herd in the present study population as Salmonella positive using serological testing at 3 different cut-off values (OD 10\%, 20\% and 40\%) and for different sample sizes (0-30) given the herd was bacteriologically positive (Salmonella isolation in the mesenteric lymph nodes). Independence between samples of a herd was assumed. 
Table V. The relative sensitivities for serological testing given one of 5 of the most-prevalent serotypes that had been isolated. In total, 492 isolates were serotyped from a pool of 1054 Salmonella isolates from mesenteric lymph nodes in Belgian slaughter pigs, isolated in 2001-2002.

\begin{tabular}{lcccc}
\hline & & \multicolumn{3}{c}{ Relative sensitivity (\%) at different cut-off values } \\
\cline { 2 - 5 } & Number of isolates & OD 10\% & OD 20\% & OD 40\% \\
\hline$S$. Typhimurium & 160 & 84.5 & $67.1^{\mathrm{a}}$ & $45.3^{\mathrm{a}}$ \\
S. Derby & 111 & 80.5 & $67.3^{\mathrm{a}}$ & $44.3^{\mathrm{a}}$ \\
S. Goldcoast & 52 & 86.8 & 58.5 & $17.0^{\mathrm{b}}$ \\
S. Panama & 36 & 72.3 & $29.7^{\mathrm{b}}$ & $10.8^{\mathrm{b}}$ \\
S. Livingstone & 33 & 88.2 & 55.9 & $20.6^{\mathrm{b}}$ \\
\hline
\end{tabular}

a,b Figures in the same column with different superscripts are significantly different from each other $(p<0.05)$.

Table VI. Serological results from pigs in which a Salmonella serotype has been isolated not belonging to serogroups B, C1 or D and thus are not supposed to be detected in the serological test used.

\begin{tabular}{lcccc}
\hline & & \multicolumn{2}{c}{ Percentage of positive serum samples at different cut-off values } \\
\cline { 3 - 5 } Serotype & Serogroup & OD 10\% & OD 20\% & OD 40\% \\
\hline S. Goldcoast & C2 & 88.5 & 59.6 & 17.3 \\
S. Bovimorbificans & C2 & 87.5 & 62.5 & 37.5 \\
S. London & E1 & 73.7 & 47.4 & 31.6 \\
$S$. Muenster & E1 & 100.0 & 100.0 & 0.0 \\
S. Urbana & N & 100.0 & 0.0 & 0.0 \\
$S$. Anatum & E1 & 80.0 & 30.0 & 10.0 \\
$S$. Sundsvall & H & 100.0 & 0.0 & 0.0 \\
\hline
\end{tabular}

coefficients at the individual level were $0.14,0.12$ and 0.09 for the cut-off values of 10,20 and 40 OD\%, respectively.

\subsection{Associations between bacteriological and serological results for the five most-occurring serotypes}

The relative sensitivity for the serological test used given one of the most-prevalent serotypes being isolated is given in Table V. Significant differences were found between the relative sensitivity for $S$. Typhimurium or $S$. Derby and the relative sensitivity for $S$. Goldcoast, $S$. Panama or $S$. Livingstone $(p<0.05)$. The percentages of serologically positive animals from which a serotype not belonging to serogroups B, C1 and D was isolated are shown in Table VI. If using the cut-off value of OD $10 \%$, the percentage of serologically positive animals varied between 73.7 and $100 \%$, depending on the serotype.

\section{DISCUSSION}

Since pork is a main source for human salmonellosis [6,29], it is important to reduce the prevalence of Salmonella in pork as much as possible. In different European countries, Salmonella control programmes that monitor the prevalence of Salmonella in pigs and pork have been implemented. Also in Belgium, a Salmonella surveillance programme is underway. Except for Norway and Sweden, where the national programme 
is based on Salmonella isolation in faecal and in lymph node samples [26], the existing control programmes are based on serological tests in which antibodies against Salmonella are measured. However, when logistic slaughtering is applied, it is the presence of Salmonella spp. in a shipment that is important regarding contamination of carcasses [5, 7, 29]. The aim of the present study was therefore to investigate the possible discrepancies between the isolation results of Salmonella and the results of serological screening methods.

The reason why we sampled the lymph nodes is that Salmonella is often present in the mesenteric lymph nodes in carrier animals [5] and that lymph nodes are the tissues most consistently colonised in infected animals [8]. Although a recent infection during transport or lairage cannot be totally excluded, the presence of Salmonella in the mesenteric lymph nodes mostly refers to an infection originating from the pig herd [14, $30]$. In the present study, transport lasted on average $1.7 \mathrm{~h}$ and the time spent in the lairage was on average $3.1 \mathrm{~h}$. Moreover, because transport of finishing pigs originating from more than one herd together in one truck is not allowed in Belgium and because of thoroughly cleaning and disinfection of the truck before every shipment, the risk for cross-contamination between pigs from different herds during transport is probably low. Although infection of the mesenteric lymph nodes during the present time span cannot be totally ruled out, we think that it has not or only marginally biased our results. To exclude the influence of transport and lairage, pooled pen faecal samples could also have been taken at the herd of origin and a correlation could have been made between the serotypes found in those samples and the serotypes isolated in the mesenteric lymph nodes. However, this was not the aim of the present study and therefore the prevalence based on Salmonella culture was estimated based on one sampling per herd.

The risk for a positive Salmonella isolation in the mesenteric lymph nodes was in the present study population 1.10 times higher when the OD\% was increasing with 10. The OR for being Salmonella culture positive for OD\% above versus below the cut-off value was slightly higher for the cutoff value of OD 10\% than for OD 20\% and $40 \%$. The lowest cut-off for serological testing had thus more discriminatory power in detecting the Salmonella harbouring pigs in comparison with higher cut-off values.

Depending on the cut-off values used, the number of culture positive herds which were serologically classified as positive varied from 83.6 (cut-off $40 \%$ ) to $100.0 \%$ (cutoff $10 \%$ ). In the group of animals that were Salmonella culture positive, only $34.5 \%$ (cut-off $40 \%$ ) or $82.8 \%$ (cut-off $10 \%$ ) were seropositive. This means that a high percentage of serologically negative animals can still harbour the pathogen and therefore, every shipment must be regarded as suspicious when using the system of logistic slaughtering.

The use of the lowest cut-off value, resulting from the relative sensitivities, was recommended in the present study population in order to increase the probability of classifying herds correctly based on serological testing. However, when using this cut-off value of OD 10\%, a higher number of herds were detected as seropositive although the animals were not harbouring the bacteria. Although Salmonella was not present in those shipments, a positive serological result at the herd level means that Salmonella is or has been present in the herd and the farmer needs to solve the problem.

The low Cohen kappa values found in the present study confirm that the agreement between both diagnostic techniques is only weak. Two major explanations for these discrepancies are possible. First, none of the diagnostic tests has a $100 \%$ sensitivity and specificity. The specificity of the ELISA test used was $99.4 \%$ as tested in a preliminary screening by the manufacturer (Idexx Inc., Maine, USA, non-published data). As shown in the present study, the sensitivity of the serological test can be influenced by 
the serotype causing the infection. The probability of serologically detecting $S$. Typhimurium or $S$. Derby, was higher than for $S$. Goldcoast, $S$. Panama or $S$. Livingstone. Similar results were obtained in the study by Van Winsen et al. [33] who concluded that some serovars may not be detected at all or may be detected to a lesser extent in different mix-ELISA currently used. Moreover, according to Nielsen et al. [18], not all pigs do seroconvert. Some serotypes can thus be isolated, without inducing detectable antibodies in the infected swine. The serological test used in the present study should be able to detect all serotypes belonging to serogroups $\mathrm{B}, \mathrm{C} 1$ and $\mathrm{D}$. However, positive serological results were also found in pigs from which serotypes belonging to other serogroups were isolated. These pigs could have been infected with other serotypes than the one isolated, at the same time or earlier in their life. If a pig was excreting more than one serotype at the same time, we were not able to detect this because only one colony per isolation plate has been serotyped. On the contrary, the range of serotypes able to be detected by the serological test is probably wider than that described. In 25 of the herds, more than one serotype was isolated. If one of those serotypes was a serotype not supposed to be detected by the serological test, the herd can still be classified correctly as positive because of the presence of detectable serotypes in the herd.

Regarding the bacteriology, the sensitivity of Salmonella isolation remains dependent on the media used $[1,32]$. Under field conditions, the culture of faecal samples is considered to have a sensitivity below 50\% [2]. In a collaborative study [12], it has been shown that the relative sensitivity of MSRV is $96 \%$ in naturally contaminated food samples. In mesenteric lymph node samples and in faecal samples, the combination of MSRV (selecting the more motile serotypes) with RV (selecting the non-motile serotypes) had a high relative sensitivity (98.4\%), as shown in preliminary experiments [21]. By using mesenteric lymph nodes instead of faecal samples and by combining two different enrichment media, we believe the sensitivity to be sufficient.

A second explanation for the discrepancy is the biological difference between the serological reaction in the animal and the presence of the pathogen. The presence of the bacteria in the lymph nodes can be caused by an infection very early in the pigs' life [27], or by a recent infection. No antibodies will be detected in the serum of these infected animals, because the serological response may no longer be there in the first case $[13,35]$ or is not yet there in the second case.

When looking at the probability distribution for different sample sizes and for different cut-off values, based on the analysis of 30 samples in the 60 study herds, a minimum sample size of 20 samples per herd would be needed, irrespective of the 3 different cut-off values, in order to classify all culture positive herds as serologically positive. If a cut-off value of OD $10 \%$ is used, a minimum sample size of 5 samples per herd would be sufficient to classify a herd correctly using serological tests.

According to the binomial distribution of the probabilities of correctly classifying a herd as serologically positive in function of the sample size, 30 serum samples should be enough for classifying all culture positive herds as serologically positive. This is in contradiction with the relative sensitivities obtained, and is due to the fact that samples of a herd are apparently not independent, as was assumed in the calculation of the sensitivities. As a consequence, the number of serum samples needed to classify Salmonella isolation positive herds as seropositive cannot be calculated based on the binomial distribution but also other factors, such as clustering of samples within a herd, should be taken into account.

The probability distribution in the present study was calculated for a within-herd prevalence of $57.3 \%$ (Salmonella isolation) or $76.8,53.3$ and 29.0 for the cut-off values of OD 10\%, 20\% and 40\% (Salmonella serol- 
ogy), respectively. If a Salmonella control programme would lead to a reduction of the Salmonella prevalence as a consequence, the minimum sample size to classify herds correctly should be re-estimated.

In conclusion, it can be stated that serological screening methods are useful at the herd level, but in the present population, a low cut-off value and an adequate number of samples is recommended to classify herds correctly. Only a weak agreement was found between the results of both diagnostic procedures. Although a herd can be classified as negative in serological screening programmes, each shipment should be regarded as suspicious with regards to logistic slaughter systems.

\section{ACKNOWLEDGEMENTS}

We thank COVAVEE for allowing us to take the samples in the slaughterhouses and for their technical assistance. The authors are also grateful to Mrs. K. Huysmans for logistic and scientific support, Mrs. B. Verbeke for her technical assistance in the PCR and to Dr M. Coryn for carefully reading the manuscript. All serum samples were analysed at the Animal Health Department-Flanders, Lier, Belgium. The project was supported by the Federal Office of Public Health, Food Safety and Environment (grant S-6009-SRI), the Catholic University of Leuven (OT/00/21) and the Institute for the Promotion of Innovation by Science and Technology in Flanders (K. Huysmans).

\section{REFERENCES}

[1] Bager F., Petersen J., Sensitivity and specificity of different methods for the isolation of Salmonella from pigs, Acta Vet. Scand. 32 (1991) 473-481.

[2] Baggesen D.L., Wegener H.C., Bager F., Stege H., Christensen J., Herd prevalence of S. enterica infections in Danish slaughter pigs determined by microbiological testing, Prev. Vet. Med. 26 (1996) 201-213.

[3] Baird-Parker A.C., Foodborne Salmonellosis, Lancet 336 (1990) 1231-1235.

[4] Berends B.R., Urlings H.A.P., Snijders J.M.A., Van Knapen F., Identification and quantifica- tion of risk factors in animal management and transport regarding Salmonella in pigs, Int. J. Food Microbiol. 30 (1996) 37-53.

[5] Berends B.R., van Knapen F., Snijders J.M.A., Mossel D.A.A., Identification and quantification of risk factors regarding Salmonella spp. on pork carcasses, Int. J. Food Microbiol. 36 (1997) 199-206.

[6] Berends B.R., Van Knapen F., Mossel D.A., Burt S.A., Snijders J.M., Impact on human health of Salmonella spp. on pork in The Netherlands and the anticipated effects of some currently proposed control strategies, Int. J. Food Microbiol. 44 (1998) 219-229.

[7] Botteldoorn N., Heyndrickx M., Rijpens N., Grijspeerdt K., Herman L., Salmonella on pig carcasses: positive pigs and cross contamination in the slaughterhouse, J. Appl. Microbiol. 95 (2003) 891-903.

[8] Carlson A.R., Blaha T., In-herd prevalence of Salmonella in 25 selected Minnesota swine farms, Swine Health Prod. 9 (2001) 7-10.

[9] Christensen J., Baggesen D.L., Soerensen V., Svensmark B., Salmonella level of Danish swine herds based on serological examination of meat-juice samples and Salmonella occurrence measured by bacteriological follow-up, Prev. Vet. Med. 40 (1999) 277-292.

[10] Corrégé I., Proux K., Fravalo P., Cornou C., Flého J.-Y., Salmonella in pig farms: characterisation and epidemiological importance of the Salmonella status of gilts, Journ. Rech. Porcine en France 34 (2002) 309-315.

[11] Davies R.H., Heath P.J., Coxon S.M., Sayers A.R., Evaluation of the use of pooled serum, pooled muscle tissue fluid (meat juice) and pooled faeces for monitoring pig herds for Salmonella, J. Appl. Microbiol. 95 (2003) 1016-1025.

[12] De Zutter L., De Smedt J.M., Abrams R., Beckers H., Catteau M., de Borchgrave J., Debevere J., Hoekstra J., Jonkers F., Lenges J., Notermans S., Van Damme L., Vandermeersch R., Verbraeken R., Waes G., Collaborative study on the use of motility enrichment on modified semisolid Rappaport-Vassiliadis medium for the detection of Salmonella from foods, Int. J. Food Microbiol. 13 (1991) 11-20.

[13] Fedorka-Cray P.J., Wipp S.C., Isaacson R.E., Nord N., Lager K., Transmission of Salmonella Typhimurium to swine, Vet. Microbiol. 41 (1994) 333-344.

[14] Fravalo P., Rose V., Eveno E., Salvat G., Madec F., Bacteriological assessment of the Salmonella status of market-aged pigs: Evolution from rearing to slaughter, Journ. Rech. Porcine en France 31 (1999) 383-389. 
[15] Lin J.-S., Tsen H.-Y., Development and use of polymerase chain reaction for the specific detection of Salmonella Typhimurium in stool and food samples, J. Food Protect. 62 (1999) 1103-1110.

[16] Lo Fo Wong D.M., Dahl J., van der Wolf P.J., Wingstrand A., Leontides L., von Altrock A., Recovery of Salmonella enterica from seropositive finishing pig herds, Vet. Microbiol. 97 (2003) 201-214.

[17] Mousing J., Jensen P.T., Halgaard C., Bager F., Feld N., Nielsen B., Nielsen J.P., BechNielsen S., Nation-wide Salmonella enterica surveillance and control in Danish slaughter swine herds, Prev. Vet. Med. 29 (1997) 247 261.

[18] Nielsen B., Baggesen D., Bager F., Haugegaard J., Lind P., The serological response to Salmonella serovars Typhimurium and Infantis in experimentally infected pigs. The time course followed with an indirect anti-LPS ELISA and bacteriological examinations, Vet. Microbiol. 47 (1995) 205-218.

[19] Nielsen B., Ekeroth L., Bager F., Lind P., Use of muscle fluid as a source of antibodies for serologic detection of Salmonella infection in slaughter pig herds, J. Vet. Diagn. Invest. 10 (1998) 158-163.

[20] Nielsen B., Alban L., Stege H., Sørensen L.L., Møgelmose V., Bagger J., Dahl J., Baggesen D.L., A new Salmonella surveillance and control programme in Danish pig herds and slaughterhouses, Berl. Münch. Tierärztl. Wochenschr. 114 (2001) 323-326.

[21] Nollet N., Maes D., De Zutter L., De Kruif A. Van Hoof J., Evaluation of different enrichment media for the isolation of Salmonella spp. from faeces and lymph nodes in slaughter pigs, in: van der Wolf P. (Ed.), Proceedings of the 4th Int. Symposium on Epidemiology and Control of Salmonella and other Foodborne Pathogens in Pork, Leipzig, Germany, September 2-5 2001, pp. 540-544.

[22] Nollet N., Maes D., De Zutter L., Duchateau L., Houf K., Huysmans K., Imberechts H., Geers R., De Kruif A., Van Hoof J., Risk factors for the herd level bacteriologic prevalence of Salmonella in Belgian slaughter pigs, Prev. Vet. Med. 65 (2004) 63-75.

[23] Osterkorn K., Czerny C.P., Wittkowski G., Huber M., Sampling plan for the establishment of a serologic Salmonella surveillance for slaughter pigs with meat juice ELISA, Berl. Münch. Tierärztl. Wschrift. 114 (2001) 30-34.

[24] Popoff M.Y., Le Minor L., Antigenic formulas of the Salmonella serovars, WHO Collaborating Centre for Reference and Research on
Salmonella, Institut Pasteur, Paris, France, 1992.

[25] Quirke A.-M. Leonard N., Kelly G., Egan J., Lynch P.B., Rowe T., Quinn P.J., Prevalence of Salmonella serotypes on pig carcasses from high- and low-risk herds slaughtered in three abattoirs, Berl. Münch. Tierärztl. Wochenschr. 114 (2001) 360-362.

[26] Sandberg M., Hopp P., Jarp J., Skjerve E., An evaluation of the Norwegian Salmonella surveillance and control program in live pig and pork, Int. J. Food Microbiol. 72 (2002) 1-11.

[27] Schwartz K.J., Salmonellosis, in: Straw B.E. et al. (Ed.), Diseases of swine, Iowa State University Press, Ames, Iowa, USA, 1999, pp. 535-551.

[28] Stege H., Christensen J., Nielsen J.P., Baggesen D.L., Enoe C., Willeberg P., Prevalence of subclinical Salmonella enterica infection in Danish finishing pig herds, Prev. Vet. Med. 44 (2000) 175-188.

[29] Steinbach G., Kroell U., Salmonella infections in swine herds - Epidemiology and importance for human diseases, Dtsch Tierärztl. Wochenschr. 106 (1999) 282-288.

[30] Swanenburg M., Berends B.R., Urlings H.A.P., Snijders J.M.A., van Knapen F., Epidemiological investigations into the sources of Salmonella contamination of pork, Berl. Münch. Tierärztl. Wochenschr. 114 (2001) 356-359.

[31] Van der Heijden H.M., First international ring trial of ELISAs for Salmonella-antibody detection in swine, Berl. Münch. Tierärztl. Wochenschr. 114 (2001) 389-392.

[32] Van derZee H., de Boer E., van Netten P., Salmonella-isolation using Modified Semisolid Rappaport-Vassiliadis (MSRV) medium, De Ware Chemicus 20 (1990) 189-199.

[33] Van Winsen R.L., van Nes A., Keuzenkamp D. Urlings H.A.P., Lipman L.J.A., Biesterveld S., Snijders J.M.A., Verheijden J.H.M., van Knapen F., Monitoring of transmission of Salmonella enterica serovars in pigs using bacteriological and serological detection methods, Vet. Microbiol. 80 (2001) 267-274.

[34] Wegener H.C., Hald T., Lo Fo Wong D., Madsen M., Korsgaard H., Bager F., Gerner-Smidt P., Mølbak K., Salmonella control programs in Denmark, Emerg. Infect. Dis. 9 (2003) 774780 .

[35] Wood R.L., Pospischil A., Rose R., Distribution of persistent Salmonella Tyhimurium infection in internal organs of swine, Am. J. Vet. Res. 50 (1989) 1015-1021. 